\title{
THE EFFECT OF POLYUNSATURATED FATTY ACIDS ON CARDIOVASCULAR RISK FACTORS AND URINARY MERCURY IN WORKERS EMPLOYED AT ELECTROLYTIC PRODUCTION OF CHLORINE
}

\section{ANNA SKOCZYŃSKA ${ }^{1}$, MACIEJ CYRAN ${ }^{2}$, BARBARA TURCZYN ${ }^{1}$, ANNA WOJAKOWSKA ${ }^{1}$, BEATA SMYK ${ }^{1}$, and MARTA SKOCZYŃSKA ${ }^{3}$}

${ }^{1}$ Wroclaw Medical University, Wrocław, Poland

Department of Internal and Occupational Medicine and Hypertension

${ }^{2}$ Maria Sklodowska-Curie Medical Academy, Warsaw, Poland

${ }^{3}$ Wroclaw Medical University, Wrocław, Poland

Department of Rheumatology and Internal Diseases

\begin{abstract}
Objectives: While inorganic mercury is being gradually withdrawn from industry, environmental exposure to mercury is recognized as one of the greatest present toxicological problems. The aim of this study was to evaluate the effect of polyunsaturated fatty acids (PUFAs) supplementation on selected cardiovascular risk factors and the urinary mercury $(\mathrm{Hg}-\mathrm{U})$ concentration in workers occupationally exposed to mercury vapor. Material and Methods: Overall, 38 workers of an electrolyzer hall (Hg-U: $46.6 \pm 35.7 \mu \mathrm{g} / \mathrm{g}$ creatinine) and a control group of 60 employees not exposed to $\mathrm{Hg}$ (Hg- $\mathrm{U}: 4.3 \pm$ $15.5 \mu \mathrm{g} / \mathrm{g}$ creatinine) were included in a clinical cross-over study. Clinical and laboratory tests were carried out 4 times: before and after a 3-month period of PUFAs supplementation (1000 mg daily), then after a 3-month break, and then after another 3-month period of PUFAs supplementation. Results: The baseline heart rate (HR) and serum triglyceride levels were higher in the Hg-exposed workers than in the controls, whereas systolic blood pressure (SBP) and cholesterol (C) levels exceeded normal values in both groups. There was a positive correlation between high-density lipoprotein 3 cholesterol $\left(\mathrm{HDL}_{3}-\mathrm{C}\right)$ and $\mathrm{Hg}-\mathrm{U}$ levels. The PUFAs use was associated with a decrease in both HR and SBP. After the first stage of supplementation, a decrease in the $\mathrm{Hg}$-U concentration was observed. In a multivariate logistic regression model, decreases in $\mathrm{Hg}$ - $\mathrm{U}$ were associated only with exposure to mercury; $\mathrm{OR}_{\Delta \mathrm{Hg}}=0.562$ (95\% CI: 0.323-0.979), $\mathrm{p}<0.042$. After the second 3-month period of PUFAs supplementation, a significant association between $\mathrm{HDL}_{3}-\mathrm{C}$ and a $\mathrm{Hg}-\mathrm{U}$ decrease was shown: $\mathrm{OR}_{\mathrm{HDL}_{3}}=1.222$ (95\% CI: 1.01-1.46), $\mathrm{p}<0.033$. Conclusions: In the workers exposed to mercury vapor, PUFAs supplementation led to some beneficial effects on HR and SBP. The first stage of supplementation was associated with a decrease in $\mathrm{Hg}-\mathrm{U}$ in which $\mathrm{HDL}_{3}$ metabolism probably plays an important role. Int J Occup Med Environ Health. 2021;34(4):551-64
\end{abstract}

Key words:

blood pressure, heart rate, HDL-C, PUFA, mercury exposure, urinary Hg

Funding: this work was supported by the Wroclaw Medical University (grant No. 2182/2016 entitled "Health status assessment of workers chronically exposed to mercury vapor in the aspect of changes resulting from supplementation with polyunsaturated fatty acids," grant manager: Anna Skoczyńska).

Received: January 16, 2020. Accepted: December 9, 2020.

Corresponding author: Anna Skoczyńska, Wroclaw Medical University, Department of Internal and Occupational Medicine and Hypertension, Borowska 213, 50-556 Wrocław, Poland (e-mail: anna.skoczynska@umed.wroc.pl). 


\section{INTRODUCTION}

Anthropogenic release of mercury occurs from manifold industrial point sources and coal-fired power plants. It is estimated that over 2000 tons of mercury are emitted annually into the atmosphere [1]. According to EU Directives and the Minamata Convention, the use of mercury in industrial technologies should be withdrawn in all countries in the world [2].

In the $\mathrm{EU}$, in the near past, occupational exposure to mercury vapor occurred mainly in electrolyzer halls during chlorine production. Until 2015, some employees of the chlor-alkali industry were still exposed to mercury vapor despite the implementation of mercury-free technologies. The main source of exposure to mercury were electrolyzers. On removal of the hardware and waste containing mercury, the contamination was spread to environment. Mercury in different chemical forms may be found in the air, such as elemental mercury in the fumes from coal-fired power plants, waste incinerators and crematoria, as well as in the water, e.g., methyl mercury compounds in fish and seafood, in the soil, e.g., in the landfills of industrial waste, and in the human body, e.g., in amalgamated dental fillings [3,4].

Metallic mercury vapors are highly toxic, affecting mainly the brain, the kidneys and the liver. Inhalation of mercury vapor causes severe pneumonia, which can often be fatal. Mercury has a high affinity for sulfhydryl groups (-SH) of aminoacids, proteins, enzymes, and sulfur-containing antioxidants such as glutathione, the most potent intracellular and mitochondrial antioxidant [5].

The least known is the effect of mercury on the cardiovascular system. However, it has been shown that mercury toxicity may be associated with hypertension, coronary heart disease, cerebrovascular accident, and carotid atherosclerosis $[5,6]$. It should be noted that in those factories in which mercury is used in the production process, factory workers are often people with many risk factors for cardiovascular diseases (CVDs), such as hypertension and lipid disorders [6]. For this reason, CVDs prevention in workers exposed to mercury vapor is especially relevant. Polyunsaturated fatty acids (PUFAs) seem to exert cardioprotective activity. Among them, omega-3 PUFAs such as eicosapentaenoic acid (EPA) and docosahexaenoic acid (DHA) may prevent CVDs through antiarrhythmic effects, blood viscosity reduction, platelet aggregation inhibition, inflammation suppression, blood vessel function improvement, as well as plasma fibrinogen and insulin resistance reduction [7]. However, people who have had a heart attack do not seem to benefit greatly from PUFAs supplementation [8]. On the other hand, in animal experiments, dietary fish oil supplements and DHA or EPA have been found to decrease myocardial infarct size [9], and to exert cardio-protective effects against ischemia and reperfusion in isolated hearts [10]. An omega-3 PUFAs-enriched diet diminishes infarct size also in humans but, to observe this effect, the omega-3/omega- 6 PUFAs ratio should be $>1: 5$ [11]. Multiple hypotheses are considered to explain the molecular mechanisms of cardio-protective omega-3 PUFAs action: the activation of the Akt pathway [8], the interaction with peroxisome proliferator-activated receptor gamma, the activation of G-protein-coupled receptors, the decrease in cyclooxygenase-2 gene expression, and the inhibition of nuclear factor $x \mathrm{~B}[12,13]$.

In addition to the effect of PUFAs on the circulatory system, there are indications that these acids reduce the toxicity of heavy metals in animals and humans [14,15]. Although the results of several systematic reviews and meta-analyses have provided insufficient evidence for the cardioprotective effects of PUFAs supplementation [16], in this study, the PUFAs wide action has become the rationale for adding PUFAs to the diet of the employees exposed to mercury in chlorine production. The aim of the study was to assess the effect of PUFAs supplementation on selected cardiovascular risk factors (heart rate [HR], blood pressure and serum lipids) and the urinary mercury ( $\mathrm{Hg}-\mathrm{U})$ 
concentration (as a measure of total mercury burden) in the workers exposed to mercury vapors, compared to the control group.

\section{MATERIAL AND METHODS}

\section{Subjects}

The study was conducted in a group of 98 male workers of a chemical factory in which mercury had been used for chlorine production. The study group consisted of 38 men aged 21-57 years, employed in the electrolyzer hall involving exposure to mercury vapors for a period of $1-40$ years. They worked in a 4-shift work system as electrolyzer operators, mechanics and shift supervisors. The electrolyzer operators' tasks included controlling the electrolyzers, pumps, water flow and sumps filling, looking for leaks in the installation, as well as washing service platforms and floors in the production hall. The mechanics were engaged in the installation, de-installation and renovation of equipment, including equipment that had come into direct contact with mercury. The shift supervisors controlled the operations for handling the processing line in the chlorine production department. All the employees were provided with standard protection (clothing, shoes, gloves, goggles, helmets and masks with mercury absorbers). The control group consisted of 60 men aged 24-66 years, working in the same chemical plants over a period of 1-42 years but without exposure to mercury.

Each man from the study and control groups was asked not to consume fish for 3 days prior to urine sample collection. This information was included in the prepared questionnaire. The purpose of limiting fish consumption was to reduce the impact of mercury originating from its main dietary source.

Based on the questionnaire, lifestyle, daily diet, modes of food preparation and stimulants intake were evaluated. The majority (55\%) of the employees who participated in the study led medium-active lifestyles. Their diet was usually rather monotonous (81\%), rich in meals that included meat. Overall, the fat dietary intake was high and exceeded the recommended daily share of fats in the majority of respondents (72\%). The most common method of preparing meals was frying and stewing. Only a small number of workers $(<1 \%)$ declared daily consumption of raw vegetables and fruit. There were no significant differences between the study and control groups in terms of diet and physical activity. The percent of people having $\leq 5$ dental amalgam fillings was similar (44.7\% and $48.3 \%$, respectively) in the study and control groups. The body mass index (BMI) was calculated based on the respondents' anthropometric data (height and body weight) collected using calibrated equipment. Blood pressure was measured using a sphygmomanometer, according to the International Protocol of the European Society of Hypertension (2003), and HR was estimated from the electrocardiogram.

No worker reported any prior CVDs or symptoms typical of mercury poisoning. Physical examinations and laboratory tests were performed 4 times:

- at the beginning of the study (stage I),

- after a 3-month period of PUFAs supplementation (stage II),

- after a 3-month break from PUFAs (stage III),

- after another 3-month use of PUFAs (stage IV).

All the respondents provided their written informed consent to participate in the study. All the procedures used were in accordance with the ethical standards of the responsible local Bioethics Committee (No. KB-125/2015) and with the Helsinki Declaration as revised in 2013.

\section{Supplementation}

In both the study and control groups, the supplemented PUFAs were Smart Omega (GALENA, Wrocław, Poland) used at a daily dose of $1000 \mathrm{mg}$ for 3 months, twice, with a 3-month break. The product was taken every day, at the same time, after the main meal. Each capsule of the supplement contained $500 \mathrm{mg}$ of fish oil including $36 \%$ of EPA and $24 \%$ of DHA. The concentration of heavy metals (lead, cadmium, mercury and arsenic) in the prepa- 
ration did not exceed the permissible limits according to Commission Regulation (EC) No. 1881/2006 of December 19, 2006. Zinc in the supplement was found at trace concentrations $(<30 \mathrm{ppm})$.

\section{Biochemical measurements}

Venous blood samples were taken after $12 \mathrm{~h}$ of fasting, and centrifuged at $1000 \mathrm{~g}$ for $20 \mathrm{~min}$ at a temperature of $4^{\circ} \mathrm{C}$. Serum samples were stored at a temperature of $-80^{\circ} \mathrm{C}$. The total serum cholesterol (TC), serum triglyceride (TG), and high-density lipoprotein cholesterol (HDL-C) levels were measured using the Spinreact enzymatic assay (SantEsteve De Bas, Girona, Spain). The low-density cholesterol (LDL-C) level was estimated among patients with a TG concentration of $<4.52 \mathrm{mmol} / \mathrm{l}(400 \mathrm{mg} / \mathrm{dl})$ by means of the Friedewald formula. The QUANTOLIP ${ }^{\circledR}$ HDL precipitation test (Technoclone $\mathrm{GmbH}$, Vienna, Austria) was used to measure the $\mathrm{HDL}_{2}-\mathrm{C}$ and $\mathrm{HDL}_{3}-\mathrm{C}$ levels. The serum non-HDL-C was calculated as a difference between the TC and HDL-C concentrations.

Urine samples were collected in the morning, before the work shift. The Hg-U concentration was determined using an atomic absorption spectrophotometer Solaar M6 by ThermoElemental Co., in addition to snap VP100 for the generation of cold vapor. The wave length used for this measurement was $\lambda=253.7 \mathrm{~nm}$ with deuterium background correction using a quartz atomization chamber. The validation parameters in the $\mathrm{Hg}-\mathrm{U}$ determination were as follows: the linear dependence of absorbance readings on mercury concentration in working solutions found for concentrations of 4-96 mg/l; the limit of detection of $0.63 \mathrm{mg} / 1$; and the limit of quantification of $1.26 \mathrm{mg} / \mathrm{l}$. Correctness, expressed as relative load (\%), was calculated on the basis of measurements of the reference material ClinChec ${ }^{\circledR}$-Controls Urine Control level I by Recipe (a concentration of $2.30 \mathrm{mg} / \mathrm{l}$ ), and amounted to $1.30 \%$. Correctness was also calculated on the basis of measurements of the reference material, i.e., Reference
Seronorm $^{\mathrm{TM}}$ Trace Elements Urine L-2 (a concentration of $44.0 \mathrm{mg} / \mathrm{l}$; whereby the sample was diluted 5 times in order to obtain a concentration of $8.8 \mathrm{mg} / \mathrm{l}$ ), and amounted to $9.02 \%$.

Repeatability, as a parameter of precision of the applied method, was 7.17\%. In 2015-2017, the laboratory participated in the G-EQUALS external quality assurance program at the University of Erlangen-Nuremberg and obtained certificates. The serum concentrations of copper and zinc were determined by flame absorption spectrometry (FAAS) in air-acetylene flame at wave lengths of $324.8 \mathrm{~nm}$ and $213.9 \mathrm{~nm}$, respectively, with deuterium background correction. Calibration curves were determined using CPI International Single-Element Cooper (Zinc) Standard at $1000 \mu \mathrm{g} / \mathrm{ml}$. Seronorm ${ }^{\mathrm{TM}}$ Trace Elements Serum certified serum metal standards were used to control the content of copper and zinc.

\section{Statistical analysis}

The results were presented as a mean \pm standard deviation $(\mathrm{M} \pm \mathrm{SD})$ or a median and interquartile range (IQR). In the case of normal distribution, paired t-tests were applied and statistical significance between the means was calculated using ANOVA tests. Non-parametric tests were used in the case of non-normal distribution; the MannWhitney $\mathrm{U}$ test and the Kolmogorov-Smirnov test were used for the comparison of 2 independent samples, the Kruskal-Wallis test with a post hoc test was used for multiple independent samples, and the Wilcoxon test or the ANOVA rank Friedman test were used for the comparison of dependent samples. Contingency tables with Fisher's exact test and the $\chi^{2}$ test were used for qualitative variables. The association between the functional and metabolic changes induced by PUFAs and $\mathrm{Hg}-\mathrm{U}$ (as a continuous variable) was analyzed in the multivariable linear regression model. The association between qualitative changes in $\mathrm{Hg}-\mathrm{U}$ (a decrease or no decrease, in the 0-1 system) and predictors was analyzed in the multivariable 
linear regression model. The correlations between variables were checked using Spearman's rank coefficient. A p-value of $<0.05$ was accepted as statistically significant. Statistical package SPSS v. 13.3 was used for statistical analysis.

\section{RESULTS}

At the beginning of the study, the mean anthropometric data and the mean period of work experience were similar in both the study and control groups. However, the mercury-exposed workers were 3 years younger on average. In all workers, about $40 \%$ were tobacco smokers and the percentage of smokers was higher in the study group (60\%) than in the control group (22\%) (Table 1). About $90 \%$ of workers in the study and control groups reported small or moderate alcohol consumption: about 18\% >5 u/month, 67\% 5-20 u/month, and 5\% > $\mathrm{u} /$ day. The most commonly consumed type of alcohol was beer.

In both groups, the median BMI value was in the overweight range. Simultaneously, the mean $C$ levels exceeded normal values, with the mean TC level of $>190 \mathrm{mg} / \mathrm{dl}$ and the mean non-HDL-C level of $>145 \mathrm{mg} / \mathrm{dl}$. The cholesterol subclasses levels were similar in the study and control groups. The mean TG concentration was significantly higher $(p<0.01)$ in the group of workers exposed to mercury.

In both groups, the mean values of blood pressure, systolic (SBP) and diastolic (DBP), were similar and slightly above the norm. The resting HR was significantly faster in the study group $(\mathrm{p}<0.01)$.

The medium Hg- $\mathrm{U}$ concentration in the men exposed to mercury vapor was many times higher in comparison to the controls $(p<0.001)$, whereas the serum copper and zinc concentrations were similar (Table 1).

In the group of all 98 workers, the 25th percentile of $\mathrm{Hg}-\mathrm{U}$ was $0.98 \mu \mathrm{g} / \mathrm{g}$ of creatinine, whereas the 75 th percentile was $32.96 \mu \mathrm{g} / \mathrm{g}$ of creatinine. The distribution of $\mathrm{Hg}-\mathrm{U}$ values was log-normal.
The analysis of all parameters depending on cigarette smoking revealed a much higher HR $(78 \pm 12$ vs. $71 \pm 9$, $\mathrm{p}<0.001)$, serum TG $(234 \pm 183$ vs. $157 \pm 92, \mathrm{p}<0.01)$ and $\mathrm{Hg}-\mathrm{U}(28.9 \pm 33.3$ vs. $15.0 \pm 30.4, \mathrm{p}<0.01)$ in smokers compared to non-smokers. Five employees who stopped smoking in the last few months were not included in the analysis.

As the number of smokers in the study and control groups was different, and as there were some differences in HR, TG and $\mathrm{Hg}-\mathrm{U}$ between smokers and non-smokers, as well as between $\mathrm{Hg}$-exposed and non-exposed workers, the impact of smoking and occupational exposure to mercury on these parameters was analyzed. In the multifactorial linear regression models, HR was associated with smoking, TG with BMI, smoking and occupational exposure to $\mathrm{Hg}$, whereas $\mathrm{Hg}-\mathrm{U}$ was associated only with occupational exposure (Table 2).

After excluding smoking from confounders, occupational exposure to $\mathrm{Hg}$ was significantly associated with $\mathrm{HR}$ ( $p=0.0047, \beta=0.2964,95 \%$ CI: $0.09-0.49$ ), as well as with TG ( $p=0.0007, \beta=0.3304,95 \%$ CI: $0.14-0.51)$ and $\mathrm{Hg}-\mathrm{U}(\mathrm{p}=0.0000, \beta=0.6991,95 \%$ CI: $0.47-0.80)$.

Two cycles of 3-month PUFAs supplementation were found to cause some functional and metabolic changes (Table 3).

Both in the study and control groups, the PUFAs-induced decrease in HR appeared together with a significant decrease in SBP. The t-tests for dependent samples showed that the changes in lipid metabolism were non-significant except for the $\mathrm{HDL}_{3}$-C level which increased after the first round of supplementation (in the study group, the difference between stages I and II was statistically significant; $p<0.05)$ and decreased after the second PUFAs supplementation in both the study and control groups (Figure 1).

Simultaneously, in the group of all 98 workers, the first supplementation with PUFAs resulted in a significant reduction ( $p<0.0001$ in the Wilcoxon pairs of order tests) 
Table 1. Characteristics of the workers occupationally exposed to mercury vapor and a control group of non-exposed men who received polyunsaturated fatty acids preparation in April 2016-April 2017 at the Wroclaw University Medical Center, Wrockaw, Poland

\begin{tabular}{|c|c|c|c|}
\hline \multirow{2}{*}{ Variable } & \multicolumn{2}{|c|}{$\begin{array}{l}\text { Participants } \\
(\mathrm{N}=98)\end{array}$} & \multirow{2}{*}{$\mathrm{p}$} \\
\hline & $\begin{array}{l}\text { mercury-exposed } \\
\quad(\mathrm{N}=38)\end{array}$ & $\begin{array}{c}\text { non-exposed } \\
(\mathrm{N}=60)\end{array}$ & \\
\hline$\overline{\text { Age [years] }(\mathrm{M} \pm \mathrm{SD})}$ & $37.6 \pm 10.2 *$ & $41.3 \pm 7.2$ & 0.0392 \\
\hline Work experience [years] (Me (IQR)) & $12.0(2.0-20.0)$ & $17.0(9.0-25.0)$ & 0.0896 \\
\hline Height $[\mathrm{cm}](\mathrm{M} \pm \mathrm{SD})$ & $1.77 \pm 0.06$ & $1.79 \pm 0.06$ & 0.1939 \\
\hline Body mass $[\mathrm{kg}](\mathrm{M} \pm \mathrm{SD})$ & $82.7 \pm 12.8$ & $86.8 \pm 11.8$ & 0.1081 \\
\hline $\mathrm{BMI}\left[\mathrm{kg} / \mathrm{m}^{2}\right](\mathrm{M} \pm \mathrm{SD})$ & $26.2 \pm 3.3$ & $27.0 \pm 3.3$ & 0.2527 \\
\hline Smokers $[\mathrm{n}(\%)]$ & $23(60.5)^{* * *}$ & $13(21.6)$ & 0.0002 \\
\hline Low/moderate alcohol drinkers [n $(\%)]$ & $34(90)$ & $54(90)$ & 0.5935 \\
\hline Amalgam fillings $>5[\mathrm{n}(\%)]$ & $2(5.2)$ & $5(8.3)$ & 0.7026 \\
\hline Heart rate $\left[\mathrm{min}^{-1}\right](\mathrm{M} \pm \mathrm{SD})$ & $78 \pm 12.2^{* *}$ & $72 \pm 8.2$ & 0.0048 \\
\hline \multicolumn{4}{|l|}{ Blood pressure $[\mathrm{mm} \mathrm{Hg}](\mathrm{M} \pm \mathrm{SD})$} \\
\hline systolic & $144 \pm 19.8$ & $142 \pm 18.3$ & 0.7148 \\
\hline diastolic & $91 \pm 12.7$ & $92 \pm 12.6$ & 0.8563 \\
\hline \multicolumn{4}{|l|}{ Cholesterol [mmol/l] $(\mathrm{M} \pm \mathrm{SD})$} \\
\hline total & $5.92 \pm 1.57$ & $5.76 \pm 0.97$ & 0.5804 \\
\hline LDL & $3.07 \pm 1.16$ & $3.43 \pm 0.91$ & 0.1101 \\
\hline \multicolumn{4}{|l|}{ HDL } \\
\hline total & $1.6 \pm 0.36$ & $1.55 \pm 0.34$ & 0.4567 \\
\hline $\mathrm{HDL}_{2}$ & $0.49 \pm 0.2$ & $0.42 \pm 0.2$ & 0.1470 \\
\hline $\mathrm{HDL}_{3}$ & $1.1 \pm 0.25$ & $1.11 \pm 0.21$ & 0.8385 \\
\hline non-HDL & $4.31 \pm 1.67$ & $4.21 \pm 0.96$ & 0.7416 \\
\hline $\mathrm{TG}[\mathrm{mmol} / \mathrm{l}](\mathrm{M} \pm \mathrm{SD})$ & $2.68 \pm 2.1^{* *}$ & $1.73 \pm 0.92$ & 0.0030 \\
\hline Creatinine- $\mathrm{U}[\mathrm{mg} / \mathrm{ml}](\mathrm{M} \pm \mathrm{SD})$ & $1.52 \pm 0.67$ & $1.78 \pm 0.67$ & 0.0600 \\
\hline $\mathrm{Hg}-\mathrm{U}[\mu \mathrm{g} / \mathrm{g}$ cre $](\mathrm{Me}(\mathrm{Q} 25 ; \mathrm{Q} 75))$ & $40.7(14.9 ; 73.9)^{* * *}$ & $1.1(0.7 ; 1.8)$ & 0.0000 \\
\hline $\mathrm{Cu}-\mathrm{S}[\mu \mathrm{g} / \mathrm{dl}](\mathrm{M} \pm \mathrm{SD})$ & $105.8 \pm 16.4$ & $105.2 \pm 15.0$ & 0.8524 \\
\hline $\mathrm{Zn}-\mathrm{S}[\mu \mathrm{g} / \mathrm{dl}](\mathrm{M} \pm \mathrm{SD})$ & $106.0 \pm 11.9$ & $103.0 \pm 13.0$ & 0.3208 \\
\hline
\end{tabular}

Creatinine-U - urine creatinine concentration; Cu-S - copper in serum; HDL - high density lipoprotein; $\mathrm{Hg}-\mathrm{U}$ - urine mercury concentration; IQR - interquartile range; LDL - low density lipoprotein; TG - triglycerides; Zn-S - zinc in serum.

Statistically significant differences in comparison to the control group: ${ }^{*} p<0.05,{ }^{* *} p<0.01,{ }^{* * *} p<0.001$.

in the $\mathrm{Hg}-\mathrm{U}$ concentration: from $21.0 \pm 3.3 \mu \mathrm{g} / \mathrm{g}$ of creatinine in stage I to $16.3 \pm 3.2 \mu \mathrm{g} / \mathrm{g}$ of creatinine in stage II. After a 3-month break in PUFAs use, mercury concen- tration increased to a level higher than the initial value $(22.0 \pm 5.0 \mu \mathrm{g} / \mathrm{g}$ of creatinine in stage III) and remained nearly unchanged after the second cycle of PUFAs sup- 
Table 2. An assessment of the relationship between the heart rate, triglycerides, urinary mercury, and smoking or occupational exposure to mercury vapor (with age and body mass index [BMI] as confounders), April 2016-April 2017, Wroclaw University Medical Center, Wrocław, Poland

\begin{tabular}{lccccc}
\hline \multicolumn{1}{r}{ Variable } & $\mathrm{b}$ & $\mathrm{t}$ & $\mathrm{p}$ & $\mathrm{b} \pm \mathrm{SD}$ & $95 \% \mathrm{CI}$ \\
\hline Heart rate & & & & & \\
age & 0.0256 & 0.197 & 0.1976 & $0.0200 \pm 0.105$ & $-0.18-(-0.22)$ \\
BMI & 0.3220 & 1.004 & 0.3177 & $0.1024 \pm 0.101$ & $-0.10-0.30$ \\
smoking & 3.1724 & 2.644 & $\mathbf{0 . 0 0 9 6}$ & $0.2907 \pm 0.109$ & $0.07-0.50$ \\
$\quad$ exposure to Hg & 1.9225 & 1.605 & 0.1119 & $0.1752 \pm 109$ & $-0.04-0.39$ \\
Serum triglycerides & & & & & \\
age & 0.1740 & 0.108 & 0.9140 & $0.0105 \pm 0.097$ & $-0.18-0.20$ \\
BMI & 11.9340 & 2.970 & $\mathbf{0 . 0 0 3 8}$ & $0.2909 \pm 0.097$ & $0.09-0.48$ \\
smoking & 30.8010 & 2.074 & $\mathbf{0 . 0 4 0 8}$ & $0.2169 \pm 0.104$ & $0.00-0.42$ \\
exposure to Hg & 35.8050 & 2.415 & $\mathbf{0 . 0 1 7 7}$ & $0.2522 \pm 0.104$ & $0.04-0.45$ \\
Urinary mercury & & & & & \\
age & 0.0028 & 0.008 & 0.9928 & $0.0007 \pm 0.084$ & $-0.16-0.16$ \\
BMI & 0.5895 & 0.731 & 0.4664 & $0.0621 \pm 0.084$ & $-0.10-0.23$ \\
smoking & -1.7178 & -0.577 & 0.5652 & $0.0522 \pm 0.090$ & $-0.23-0.12$ \\
exposure to Hg & 21.8291 & 7.351 & $\mathbf{0 . 0 0 0 0}$ & $0.6633 \pm 0.090$ & $0.48-0.84$ \\
\hline
\end{tabular}

Parameterization with sigma-restrictions in the linear regression model. Bolded are $\mathrm{p}<0.05$.

plementation $(21.9 \pm 6.4 \mu \mathrm{g} / \mathrm{g}$ of creatinine in stage IV). However, the $\mathrm{Hg}-\mathrm{U}$ concentration distribution differed between the study and control groups. Although a significant decrease in $\mathrm{Hg}-\mathrm{U}$ was observed after the first period of PUFAs supplementation in both mercury-exposed workers and the control group, measurements at stages III and IV revealed a persistent decrease in $\mathrm{Hg}-\mathrm{U}$ in the study group and a return of $\mathrm{Hg}-\mathrm{U}$ to initial values in the control group (Table 3, Figure 2).

Different $\mathrm{Hg}-\mathrm{U}$ changes at individual time points were not accompanied by other intergroup differences in PUFAs effects (Table 3).

A multivariate logistic regression model was used to answer the question of whether there was an association between a decrease in $\mathrm{Hg}-\mathrm{U}$ (with a decrease or no decrease in $\mathrm{Hg}-\mathrm{U}$ expressed in the $0-1$ system as the qualita- tive variable) induced by the first or second PUFAs supplementation, and smoking or exposure to mercury (qualitative predictors). Age, BMI, the duration of exposure to mercury and lipid levels (TC, LDL-C, HDL-C, $\mathrm{HDL}_{2}-\mathrm{C}$, $\mathrm{HDL}_{3}-\mathrm{C}$ and $\mathrm{TG}$, measured before each PUFAs supplementations) were used as potential quantitative predictors. A multifactorial model was built by the backward stepwise approach in the logistic regression method using a validation mechanism based on a v-fold cross-scoring in 12 steps.

After the first 3-month period of PUFAs supplementation, only a significant association between the decrease in $\mathrm{Hg}-\mathrm{U}$ concentration and exposure to mercury was observed: $\mathrm{OR}_{\Delta \mathrm{Hg}}=0.562$ (95\% CI: 0.323-0.979), $\mathrm{p}<0.042$.

After the second 3-month period of PUFAs supplementation, no significant associations between changes in 


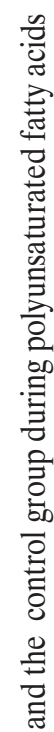

产

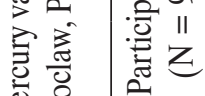

:

혼

牙

क्षे

की :

亲

竞

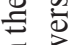

品

急

ฐั

实

离

苨

츨

응

荧

롬

츨

.요

龸.

氜

$\dot{0}$

递

|

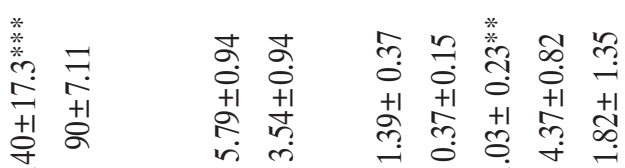

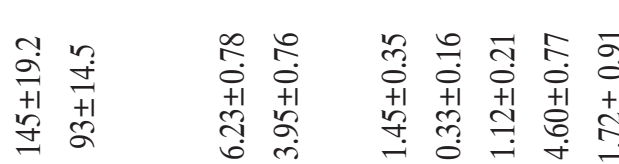

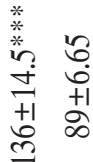

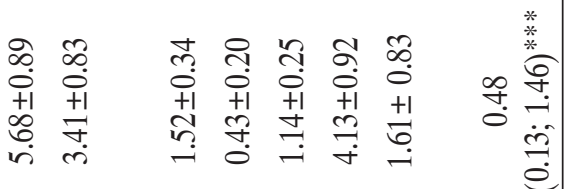

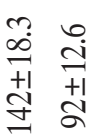

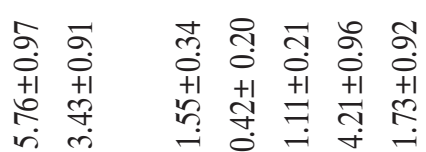

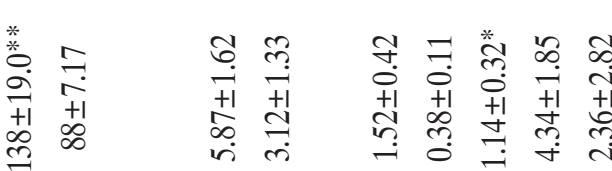

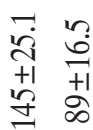

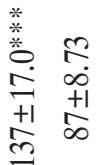

in

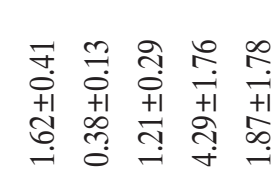

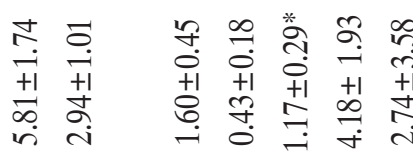

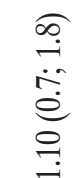

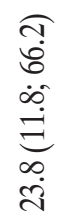

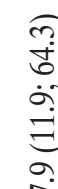

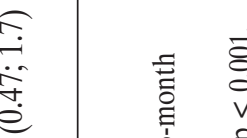

ปิ

命

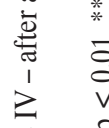

兽

蓄

击

总

寻

竞

离

馬

氙

$\stackrel{1}{\stackrel{1}{\circ}}$

焉 㐘

.0

善

흘

穿

离壱

完 离

离 总

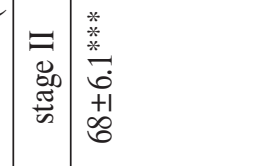

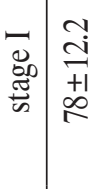

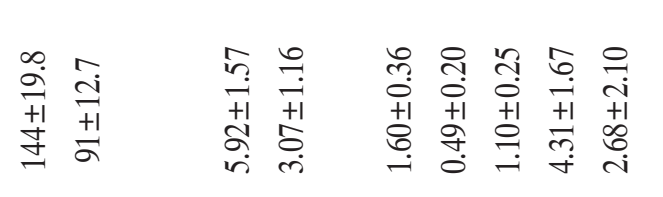

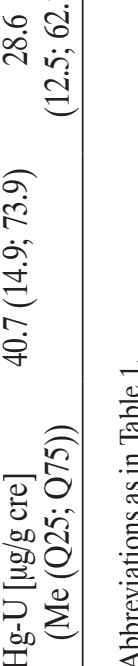

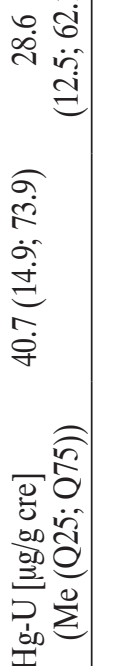

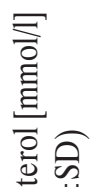

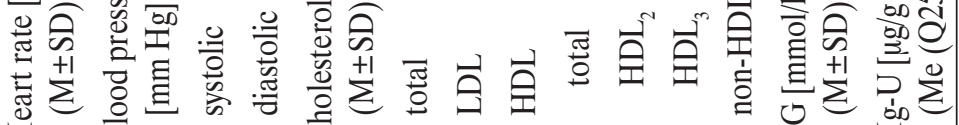

ल)

苛 离

$\stackrel{1}{\stackrel{2}{*}}$

踏

害

营. 造

(c) on

政

.

\% 0 产.

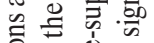

.

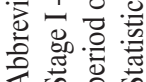




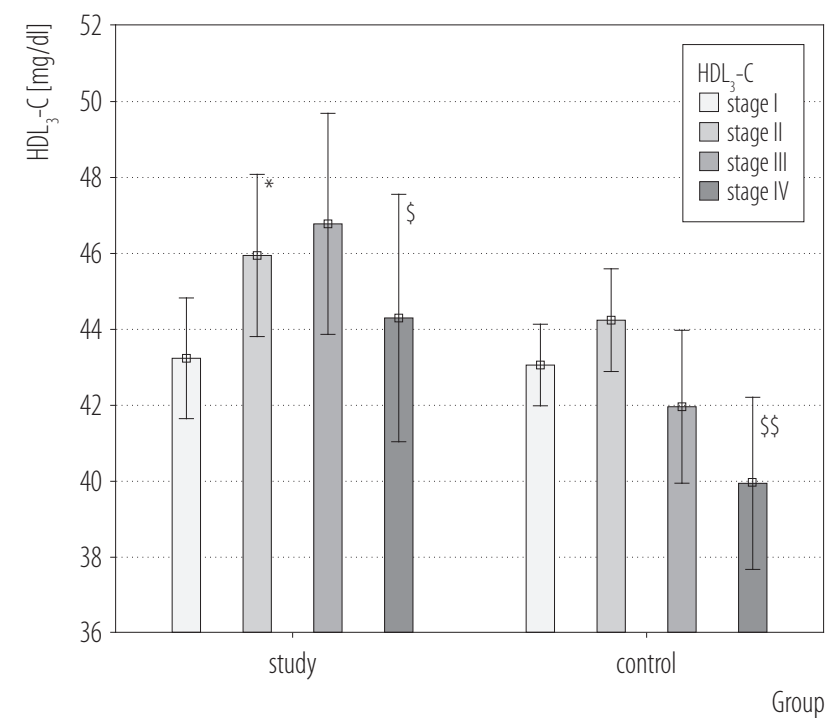

Data given as $\mathrm{M} \pm \mathrm{SD}$.

Stages as in Table 3.

A statistically significant difference between $\mathrm{HDL}_{3}-\mathrm{C}$ values measured at stages I and II: ${ }^{*} \mathrm{p}<0.05$.

A statistically significant difference between $\mathrm{HDL}_{3}-\mathrm{C}$ values measured at stages III and IV: ${ }^{\$} \mathrm{p}<0.05 ;{ }^{\$ \$} \mathrm{p}<0.01$.

Figure 1. The high-density lipoprotein 3 cholesterol ( $\mathrm{HDL}_{3}-\mathrm{C}$ ) in the workers exposed to mercury vapor and the control group during polyunsaturated fatty acids supplementation in April 2016-April 2017 at the Wroclaw University Medical Center, Wroclaw, Poland

the $\mathrm{Hg}-\mathrm{U}$ concentration and predictors were found. However, the parameter evaluation showed an association between $\mathrm{HDL}_{3}-\mathrm{C}$ and a $\mathrm{Hg}-\mathrm{U}$ decrease: $\mathrm{OR}_{\mathrm{HDL}_{3}}=1.222$ (95\% CI: 1.01-1.46, p < 0.033). Attention should also be paid to the positive linear relationship between $\mathrm{Hg}-\mathrm{U}$ and $\mathrm{HDL}_{3}-\mathrm{C}$ at the beginning of the study $(\mathrm{p}<0.01)$ (Figure 3).

There was no significant relationship between serum trace metals and $\mathrm{Hg}-\mathrm{U}$ concentrations. Over the period of observations, serum copper and zinc levels remained similar to the initial values in both the study group $(\mathrm{Cu}: 106.5 \pm$ $18.1 \mathrm{mg} \%$ vs. $105.7 \pm 13.9 \mathrm{mg} \%$ and $\mathrm{Zn}: 113.9 \pm 16.8 \mathrm{mg} \%$ vs. $106.0 \pm 11.9 \mathrm{mg} \%)$ and the control group (Cu: $105.7 \pm$ $13.9 \mathrm{mg} \%$ vs. $105.2 \pm 15.0 \mathrm{mg} \%$ and $\mathrm{Zn}: 109.1 \pm 13.6 \mathrm{mg} \%$ vs. $103.3 \pm 13.0 \mathrm{mg} \%$ ).

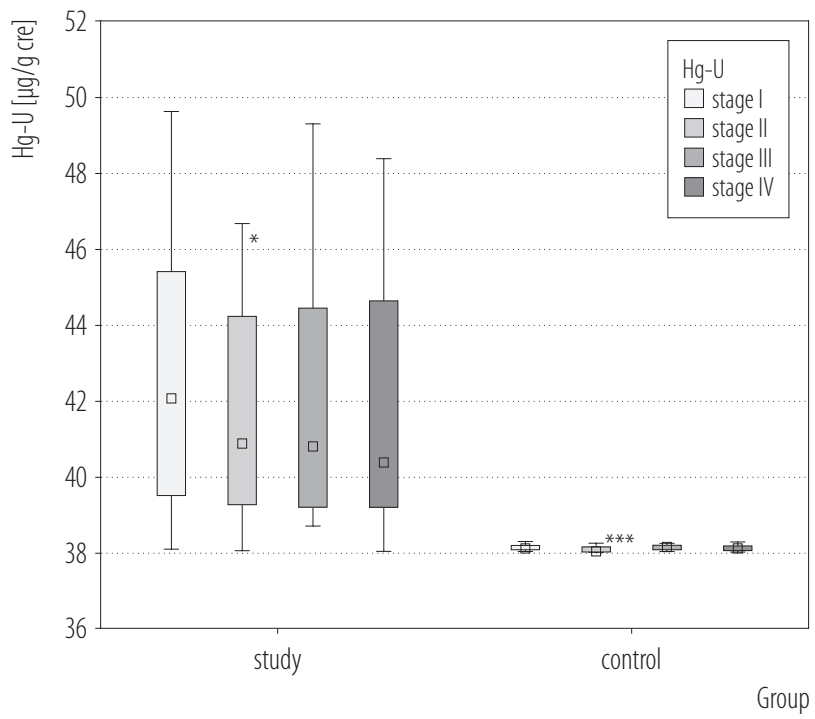

The box-plot represents median and Q25; Q75, whiskers in the box-plot - a range of min.-max values.

Stages as in Table 3.

Statistically significant differences between the $\mathrm{Hg}-\mathrm{U}$ measured at stages I and II: * $\mathrm{p}<0.05 ;{ }^{* * *} \mathrm{p}<0.001$.

Figure 2. The mercury urine concentration $(\mathrm{Hg}-\mathrm{U})$ in the workers exposed to mercury vapor and the control group during polyunsaturated fatty acids supplementation in April 2016-April 2017 at the Wroclaw University Medical Center, Wroclaw, Poland

\section{DISSCUSSION}

Occupational or environmental exposure to heavy metals such as lead, cadmium, and mercury is known to be associated with increased cardiovascular morbidity and mortality $[5,6]$. Some researchers suggest that mercury or lead toxicity should be evaluated in any patient with coronary atherosclerosis, cerebrovascular accident or hypertension [6].

Since PUFAs seem to have a cardio-protective role, in the authors' opinion, their preventive use in middle-aged men occupationally exposed to mercury vapor was justified. The PUFAs supplementation in the group of workers with high levels of HG-U $(46.6 \pm 35.7 \mu \mathrm{g} / \mathrm{g}$ creatinine) was further justified as there were other cardiovascular risk factors present, such as smoking ( $60 \%$ of workers), elevated TG levels, increased HR and a tendency to elevated blood 


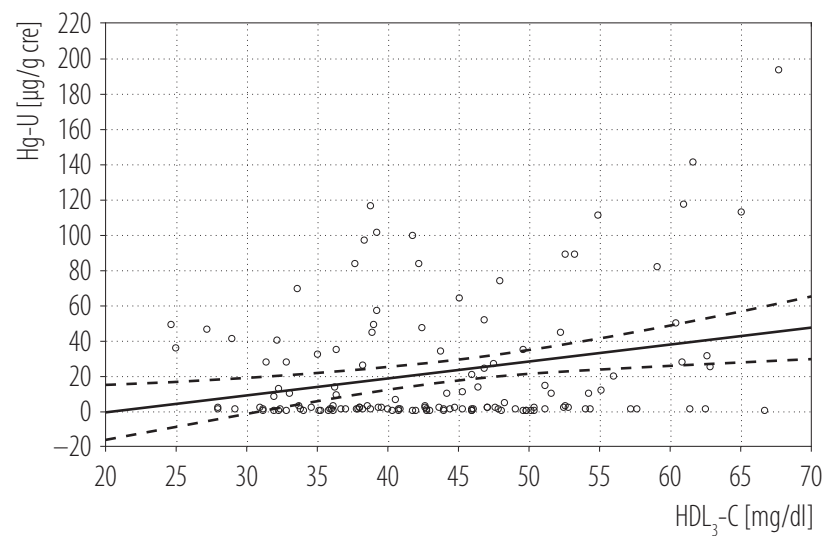

Figure 3. The correlation between the serum high-density lipoprotein 3 cholesterol ( $\mathrm{HDL}_{3}-\mathrm{C}$ ) and mercury urine concentration $(\mathrm{Hg}-\mathrm{U})$ in the workers exposed to mercury vapor and the control group during polyunsaturated fatty acids supplementation in April 2016-April 2017 at the Wroclaw University Medical Center, Wroclaw, Poland

pressure. The main reason for the increased $\mathrm{HR}$ and $\mathrm{TG}$ may have been smoking, as the number of smokers among the mercury-exposed workers was significantly higher than in the non-exposed group. Moreover, in the multifactorial linear regression model, smoking was significantly associated with heart rate as well as with serum TG (Table 2). However, increased HR and TG may have also resulted from a higher mercury body burden in the workers exposed to mercury vapor. After excluding smoking from confounders, occupational exposure to $\mathrm{Hg}$ was still significantly associated with both HR and TG ( $p<0.01$ and $\mathrm{p}<0.001$, respectively).

In other studies, populations occupationally exposed to mercury exhibited an increased resting HR and/or hypertriglyceridemia, even after considering traditional risk factors and exposure to other heavy metals $[17,18]$. Increased resting HR and affected HR variability in the mercury-exposed population have been explained as consequences of increased sympathetic or decreased parasympathetic activity [17]. The hypothesis about the impaired sympathovagal control of the heart was confirmed in experimental studies performed on rats poisoned with low-dose inor- ganic mercury [18]. However, the results of other studies on adults with environmental exposure to mercury were heterogeneous and did not show any consistent associations between mercury concentrations and cardiac autonomic function [19].

In this study, workers exposed to mercury, similar to controls, displayed mean SBP values above the accepted norm. This is compatible with the results obtained in other studies $[6,18]$. In the meta-analysis, a significant positive association between mercury levels and blood pressure values was identified [7]. In this study, a correlation between mercury levels and blood pressure was not shown. Also, in some other studies, no significant association between blood mercury and SBP or DBP was observed [20,21].

Notably, PUFAs, when supplemented for 6 months as was done in this study, led to a significant decrease in HR and SBP, in both the study and control groups. These beneficial changes in the cardiovascular system were undoubtedly associated with PUFAs supplementation; they appeared after the first period of supplementation, were no longer observed after the break in the supplementation and then reoccurred after the second period of PUFAs supplementation. These effects of PUFAs on the circulatory system are known [22,23] and were expected. However, the surprising and more interesting result of this study was that PUFAs significantly reduced the $\mathrm{Hg}-\mathrm{U}$ concentration after a 3-month supplementation period. This statistically significant $\mathrm{Hg}-\mathrm{U}$ decrease was observed in both the study and control groups. In the logistic regression model, the PUFA-induced $\mathrm{Hg}$-U decreases were significantly dependent only on occupational exposure to mercury. In the Hg-exposed workers, these $\mathrm{Hg}-\mathrm{U}$ decreases were less frequent than in the control group. And, vice versa, in the control group (environmentally exposed to $\mathrm{Hg}$ ), the chance for a reduction in $\mathrm{Hg}-\mathrm{U}$ by PUFAs was greater than for people exposed professionally to mercury.

The Hg-U concentration is an indicator of chronic exposure to mercury, in contrast to the mercury concentration 
in the blood, which is an indicator of acute exposure, or the concentration of mercury in the hair, which is a good indicator of fish consumption $[24,25]$. The association between PUFAs and $\mathrm{Hg}$-U may be important in the context of the environmental exposure to mercury, e.g., a common use of fish as an important source of both PUFAs and mercury.

The mechanism behind the observed changes in the $\mathrm{Hg}-\mathrm{U}$ concentration is unclear. It is worth noting that relatively small doses of PUFAs were used in the study, which did not affect lipid concentration, apart from the effect on $\mathrm{HDL}_{3}$-C. On the other hand, the authors demonstrated the positive linear correlation between $\mathrm{HDL}_{3}-\mathrm{C}$ and $\mathrm{Hg}-\mathrm{U}$ at the beginning of the study.

Mortazavi et al. [26] showed a positive dependence between serum HDL-C and the blood mercury concentration in a group of 3713 Korean men with metabolic syndrome. The authors hypothesized that the elevated blood mercury concentration may have been a factor that led to an increase in the serum HDL-C concentration in these men. In fact, $\mathrm{HDL}_{3}$ is the predominant $\mathrm{HDL}$ subclass with a density range of about $1.125-1.21 \mathrm{~g} / \mathrm{ml}$. It is a protein-enriched subclass (the mean protein-to-lipid ratio is $55: 45$ by weight), with apoA-I and apoA-II as the major structural peptides. There are currently some discrepancies between the preclinical and clinical data regarding the beneficial role of $\mathrm{HDL}_{2}$ and $\mathrm{HDL}_{3}$ in cardiovascular prevention, with more evidence pointing to $\mathrm{HDL}_{3}$ [27]. On the other hand, an increase in these HDL subclasses does not always mean an improvement in the cardio-protective potential [27].

Mercury effects included the appearance of acute phase proteins [28], which might be associated with impaired HDL function [29]. Lately, it was shown that mercury might be responsible for the existence of dysfunctional HDL through inactivation of paraoxonase, an extracellular anti-oxidative enzyme related to HDL. Such a dysfunction in HDL can manifest itself as an impairment in the reverse cholesterol transport, anti-inflammatory, an- tioxidant and antithrombotic functionalities [5]. In other studies, $\mathrm{Hg}-\mathrm{U}$ was positively and significantly related to total- and oxy-LDL-C, indicating mercury as an indirect cardiovascular risk factor [30].

In this study, in the group of workers with high $\mathrm{Hg}-\mathrm{U}$, a small but significant increase in $\mathrm{HDL}_{3}$ after the first PUFAs supplementation and, similar to the control group, a decrease in $\mathrm{HDL}_{3}$ after the second PUFAs supplementation were observed. It is uncertain whether these changes in the serum $\mathrm{HDL}_{3}$ are connected with the changes in $\mathrm{Hg}-\mathrm{U}$ observed during PUFAs use. It is possible as there is a close connection between $\mathrm{HDL}_{3}$ and PUFAs metabolism. On the level of the cellular membrane, $\mathrm{HDL}_{3}$ stimulates the conversion of phosphatidylethanolamine into phosphatidylcholine through a sequence of 3 trans-methylation reactions, leading to PUFAs entry into the brain [31]. The $\mathrm{HDL}_{3}$ particle, while participating in trans-methylation reactions, could also participate in PUFAs entry into the kidney. It is probable since the reno-protective effects of long-chain omega-3 PUFAs supplements have been observed [32].

Inhaled elemental mercury is absorbed through the mucous membrane of the lungs, rapidly oxidized to other forms, and stimulating the synthesis of metallothionein, it is cumulated mainly in the kidney [33]. Given that an approximately linear relationship between mercury in the kidney and mercury in urine was documented [34], the decrease in $\mathrm{Hg}$-U after the first PUFAs supplementation may reflect a decreased mercury accumulation in the kidney. It would be consistent with the observation that omega-3 PUFAs attenuate mercury toxicity in the kidney [35]. In turn, an association between $\mathrm{HDL}_{3}-\mathrm{C}$ and the decrease in $\mathrm{Hg}-\mathrm{U}$ after the second PUFAs supplementation, and the positive linear relationship between $\mathrm{HDL}_{3}-\mathrm{C}$ and the $\mathrm{Hg}$-U levels at the beginning of the study, seem to confirm the interaction between mercury and $\mathrm{HDL}_{3}-\mathrm{C}$.

The limitations of this study include a small size of the study group (38 workers exposed to mercury vapor). 
Another limitation is the lack of a control group of subjects with no previous exposure to mercury, since the control individuals involved in the study were exposed to low mercury levels due to local pollution. Although the effect of PUFAs on $\mathrm{Hg}-\mathrm{U}$ and the relationship between $\mathrm{Hg}-\mathrm{U}$ and $\mathrm{HDL}_{3}$ found in this study were statistically significant, the size effects were small suggesting that further studies would be necessary.

It needs to be highlighted that the presented study concerning the consequences of occupational exposure to mercury vapor may be one of the last such studies in Europe thanks to new technologies of mercury-free chlorine production. In the future, results of these studies can provide reference in the interpretation of the health effects of mercury present in the environment. The authors believe that the results of their study warrant research in a wider population.

In summary, the results of this study indicate that elevated baseline HR, TG and SBP in the workers with high $\mathrm{Hg}-\mathrm{U}$ levels are associated with smoking as well as occupational exposure to mercury. A low-dose PUFAs supplementation $(1000 \mathrm{mg} /$ day $)$, while having no significant effect on TG, reduced HR and SBP in the workers both with low and elevated $\mathrm{Hg}-\mathrm{U}$ levels. In addition to the PUFAs beneficial effects on the cardiovascular system, after the first 3 months of supplementation a decrease in $\mathrm{Hg}-\mathrm{U}$ levels, accompanied by an increase in serum $\mathrm{HDL}_{3}-\mathrm{C}$, was observed both in the study and control groups. The relationship between $\mathrm{HDL}_{3}-\mathrm{C}$ and a decrease in $\mathrm{Hg}-\mathrm{U}$ was confirmed in the multivariate logistic regression model.

\section{CONCLUSIONS}

The PUFAs supplementation at a small dose of $1000 \mathrm{mg}$ daily for 3 months in the workers exposed to mercury vapor leads to a decrease in HR and SBP, as well as to a decrease in the $\mathrm{Hg}-\mathrm{U}$ concentration after the first cycle of PUFAs supplementation. The effect of PUFAs on $\mathrm{Hg}-\mathrm{U}$ is possibly mediated by the $\mathrm{HDL}_{3}$ metabolism. The PUFAs supplementation might be beneficial in populations environmentally exposed to mercury which warrants further studies.

\section{REFERENCES}

1. Pirrone N, Cinnirella S, Feng X, Finkelman RB, Friedli HR, Leaner J. Global mercury emissions to the atmosphere from anthropogenic and natural sources. Atmos Chem Phys. 2010;10(13):5951-64, https://doi.org/10.5194/acp-10-5951-2010.

2. Larson HJ. The Minamata Convention on Mercury: risk in perspective. Lancet. 2014;383(9913):198-9, https://doi.org/ 10.1016/S0140-6736(13)62000-0.

3. Castro MS, Sherwell J. Effectiveness of Emission Controls to Reduce the Atmospheric Concentrations of Mercury. Environ Sci Technol. 2015;49(24):14000-7, https://doi.org/10.1021/ acs.est.5b03576.

4. Maulvault AL, Anacleto P, Barbosa V, Sloth JJ, Rasmussen RR, Tediosi A, et al. Toxic elements and speciation in seafood samples from different contaminated sites in Europe. Environ Res. 2015;143(part B):72-81, https://doi.org/ 10.1016/j.envres.2015.09.016.

5. Genchi G, Sinicropi MS, Carocci A, Lauria G, Catalano A. Mercury Exposure and Heart Diseases. Int J Environ Res Public Health. 2017;14(1):74, https://doi.org/10.3390/ijerph 14010074.

6. Houston MC. Role of Mercury Toxicity in Hypertension, Cardiovascular Disease and Stroke. J Clin Hypertens. 2011;13: 621-7, https://doi.org/10.1111/j.1751-7176.2011.00489.x.

7. Feng Hu X, Singh K, Chan HM. Mercury Exposure, Blood Pressure, and Hypertension: A Systematic Review and Doseresponse Meta-analysis. Environ Health Perspect. 2018;126 (7):076002, https://doi.org/10.1289/EHP2863.

8. Endo J, Arita M. Cardioprotective mechanism of omega-3 polyunsaturated fatty acids. J Cardiol. 2016;67(1):22-7.

9. Desnoyers M, Gilbert K, Rousseau G. Cardioprotective Effects of Omega-3 Polyunsaturated Fatty Acids: Dichotomy between Experimental and Clinical Studies. Mar Drugs. 2018;16(7):234, https://doi.org/10.3390/md16070234. 
10. Rhee JJ, Kim E, Buring JE, Kurth T. Fish Consumption, Omega-3 Fatty Acids, and Risk of Cardiovascular Disease. Am J Prev Med. 2017;52(1):10-9, https://doi.org/10.1016/ j.amepre.2016.07.020.

11. Zhu BQ, Sievers RE, Sun YP, Morse-Fisher N, Parmley WW, Wolfe CL. Is the reduction of myocardial infarct size by dietary fish oil the result of altered platelet function? Am Heart J. 1994;127(4):744-55, https://doi.org/10.1016/00028703(94)90540-1.

12. Yang BC, Saldeen TG, Bryant JL, Nichols WW, Mehta JL. Long-term dietary fish oil supplementation protects against ischemia-reperfusion-induced myocardial dysfunction in isolated rat hearts. Am Heart J. 1993;126(6):1287-92, https:// doi.org/10.1016/0002-8703(93)90524-D.

13. Simopoulos AP. The importance of the ratio of omega- $6 /$ omega-3 essential fatty acids. Biomed Pharmacother. 2002;56: 365-79, https://doi.org/10.1016/S0753-3322(02)00253-6.

14. Houston MC. The Role of Mercury in Cardiovascular Disease. J Cardiovasc Dis Diagn. 2014;2(5)170-8, https://doi. org/10.4172/2329-9517.1000170.

15. Singh PK, Nath R, Ahmad MK, Rawat A, Babu S, Dixit RK. Attenuation of lead neurotoxicity by supplementation of polyunsaturated fatty acid in Wistar rats. Nutr Neurosci. 2016;19(9):396-405.

16. Rizos EC, Ntzani EE, Bika E, Kostapanos MS, Elisaf MS. Association between omega-3 fatty acid supplementation and risk of major cardiovascular disease events: a systematic review and meta-analysis. JAMA. 2012;308(10):1024-33, https://doi.org/10.1001/2012.jama.11374.

17. Poręba R, Skoczyńska A, Gać P, Turczyn B, Wojakowska A. Left ventricular diastolic function in workers occupationally exposed to mercury vapour without clinical presentation of cardiac involvement. Toxicol Appl Pharmacol. 2012(3);263:368-73.

18. Simões MR, Azevedo BF, Fiorim J, Freire DDJ, Covre EP, Vassallo DV, et al. Chronic mercury exposure impairs the sympathovagal control of the rat heart. Clin Exp Pharmacol Physiol. 2016;43(11):1038-45, https://doi.org/10.1111/ 1440-1681.12624.
19. Gribble MO, Cheng A, Berger RD, Rosman L, Guallar E. Mercury Exposure and Heart Rate Variability: a Systematic Review. Curr Environ Health Rep. 2015;2:304-14, https:// doi.org/10.1007/s40572-015-0053-0.

20. Valera B, Dewailly E, Poirier P. Impact of mercury exposure on blood pressure and cardiac autonomic activity among Cree adults (James Bay, Quebec, Canada). Environ Res. 2011;111(8):1265-70.

21. Rajaee M, Sánchez BN, Renne EP, Basu N. An Investigation of Organic and Inorganic Mercury Exposure and Blood Pressure in a Small-Scale Gold Mining Community in Ghana. Int J Environ Res Public Health. 2015;12(8):10020-38, https://doi.org/10.3390/ijerph120810020.

22. Hidayat K, Yang J, Zhang Z, Chen GC, Qin LQ, Eggersdorfer M, et al. Effect of omega-3 long-chain polyunsaturated fatty acid supplementation on heart rate: a meta-analysis of randomized controlled trials. Eur J Clin Nutrition. 2018;72(6):805-17, https://doi.org/10.1038/s41430-017-0052-3.

23. Virtanen JK, Nyantika AN, Kauhanen J, Voutilainen S, Tuomainen TP. Serum long-chain n-3 polyunsaturated fatty acids, methylmercury and blood pressure in an older population. Hypertens Res. 2012;35(10):1000-4.

24. Castaño A, Pedraza-Díaz S, Cañas AI, Pérez-Gómez B, Ramosa JJ, Bartoloméa M, et al. Mercury levels in blood, urine and hair in a nation-wide sample of Spanish adults. Sci Total Environ. 2019;13:262-70, https://doi.org/10.1016/ j.scitotenv.2019.03.174.

25. Kruzikova K, Modra H, Kensova R, Skočovská B, Wlasow T, Svoboda T, et al. Mercury in human hair as an indicator of the fish consumption. Neuro Endocrinol Lett. 2008;29(5):675-9.

26. Mortazavi SM, Mortazavi G, Paknahad M. Positive correlation of serum HDL cholesterol with blood mercury concentration in metabolic syndrome Korean men (analysis of KNANES 2008-2010, 2013). J Endocrinol Invest. 2016;39:1363-4.

27. Albers JJ, Slee A, Fleg JL, O'Brien KD, Marcovina SM. Relationship of baseline HDL subclasses, small dense LDL 
and LDL triglyceride to cardiovascular events in the AIMHIGH clinical trial. Atherosclerosis. 2016;251:454-9, https:// doi.org/10.1016/j.atherosclerosis.2016.06.019.

28. Ghosh N, Bhattacharya S. Acute phase response of rabbit to $\mathrm{HgCl} 2$ and $\mathrm{CdCl} 2$. Biomed Environ Sci. 1993;6(1):1-7.

29. Khovidhunkit W, Shigenaga JK, Moser AH, Feingold KR, Grunfeld C. Cholesterol efflux by acute-phase high density lipoprotein: role of lecithin: cholesterol acyltransferase. J Lipid Res. 2001;42:967-75.

30. Kim DS, Lee EH, Yu SD, Cha JH, Ahn SC. Heavy metal as risk factor of cardiovascular disease - an analysis of blood lead and urinary mercury. J Prev Med Public Health. 2005;38(4):401-7.

31. Magret V, Elkhalil L, Nazih-Sanderson F, Martin F, Bourre JM, Fruchart JC, et al. Entry of polyunsaturated fatty acids into the brain: Evidence that high-density lipoprotein-induced methylation of phosphatidylethanolamine and phospholipase A2 are involved. Biochem J. 1996;316(3):805-11, https://doi.org/10.1042/bj3160805.
32. Miller ER, Juraschek SP, Anderson CA, Guallar E, HenochRyugo K, Charleston J, et al. The Effects of n-3 Long-Chain Polyunsaturated Fatty Acid Supplementation on Biomarkers of Kidney Injury in Adults With Diabetes. Results of the GO-FISH trial. Diabetes Care. 2013;36(6):1462-9, https://doi.org/10.2337/dc12-1940.

33. Akerstrom M, Barregard L, Lundh T, Sallsten G. Relationship between mercury in kidney, blood, and urine in environmentally exposed individuals, and implications for biomonitoring. Toxicol Appl Pharmacol 2017;320:17-25, https://doi. org/10.1016/j.taap.2017.02.007.

34. Li H, Lin X, Zhao J, Cui L, Wang L, Gao Y, et al. Intestinal Methylation and Demethylation of Mercury. Bull Environ Contam Toxicol. 2019;102(5):597-604, https://doi. org/10.1007/s00128-018-2512-4.

35. Karapehlivan M, Ogun M, Kaya I, Ozen H, Deveci HA, Karaman M. Protective effect of omega-3 fatty acid against mercury chloride intoxication in mice. J Trace Elem Med Biol. 2014;28:94-9, https://doi.org/10.1016/j.jtemb.2013.08.004.

This work is available in Open Access model and licensed under a Creative Commons Attribution-NonCommercial 3.0 Poland License - http://creativecommons.org/ licenses/by-nc/3.0/pl/deed.en. 